\title{
GUINEA ECUATORIAL COMO PREGUNTA ABIERTA: HACIA EL DIÁLOGO ENTRE NUESTRAS OTREDADES
}

\author{
POR \\ Lola Aponte y Elisa Rizo
}

Número dedicado a Marvin Lewis

\section{I.}

La invitación de este dossier es la siguiente: rehusarse a la ambigüedad y al enigma que descansa del lado del otro. La aspiración sería en este dialogo hacer el ejercicio de leer como escuchar, lo que significa quebrar el lenguaje y cada una de sus palabras para volverlas nuevas, contendoras de significaciones insospechadas. Quizás entonces ocurra la consecuencia más temida: el diálogo entre nuestras otredades. Así, esta letra africana en español nos expone a la posibilidad de desgarrar las ordenaciones que se nos han vuelto sustantivas. Leer, no para servirnos de un registro de inequidades, antes bien para evidenciar el poder de lo simbólico. Lanzarnos al espacio indeterminado de ese diálogo en el que sintaxis, significación, hablantes y óptimamente lectores corremos el riesgo constante de ser modificados.

Central a esta invitación es recordar que Guinea Ecuatorial, el único país Subsahariano que habla español, nos es desconocido. Y en parte esto sucede por las limitaciones inherentes a las categorías que pudieran predisponer un primer acercamiento: ubicación geográfica, historia colonial, lengua, discurso nacional, etc. Tal pareciera que en el marco de la literatura hispánica, la geografía y la lengua convierten a este país en un excedente perpetuo. Demasiado lejano de las Américas para que quepa en ese singular y ya difuso mundo que es Iberoamérica y ausente de la historia cultural de la Península Ibérica, Guinea Ecuatorial es más que nada una pregunta. Precisamente es esta lejanía geográfica junto a su identidad hispana, lo que le aleja de otras tradiciones literarias africanas en lengua europea. Bordeado por países francófonos, sus autores han visto un aislamiento lingüístico que ha limitado, hasta cierto punto, su reconocimiento dentro del continente africano. ${ }^{1}$

Ver "The Missing Link: African Hispanism at the Dawn of the Millenium" de Mbare Ngom para una exposición del hispanismo desde el punto de vista de escritores y un marco de las circunstancias 
Sin embargo, este aislamiento, sobre todo en lo que respecta a la dimensión iberoamericana, es también resultado de una fraccionada relación con potencias europeas. Varias capas colonizadoras se sedimentan sobre este país cuya geografía, por el arbitrario establecimiento de fronteras coloniales, resulta igualmente fragmentada. La historia colonial reporta las múltiples etnias que tanto en las islas como en el espacio continental aseguraron su subsistencia mediante una férrea resistencia ${ }^{2}$ o por negociaciones ya intertribales, ya con las naciones imperiales que les ocupaban. Así, entre los siglos XV y XX la historia de los guineanos se vio marcada por proyectos coloniales de portugueses y británicos, para finalmente ser colonizada por España. A través de este tiempo colonial, en el que avanzó el capitalismo, Guinea Ecuatorial se constituyó en un suplidor de materia prima necesaria para este desarrollo: cacao y madera, relacionando su crecimiento al de Europa y al de las Américas.

El confinamiento de Guinea Ecuatorial ha sido continuado después de la independencia de España en 1968 a causa de las dictaduras sucesivas (de Francisco Macías Nguema, 1968-1979 y de Teodoro Obiang, 1979-presente) que han definido la vida poscolonial de este país y que han sido bien conocidas por su falta de respeto por los derechos humanos de la población. Esencial en este desarrollo ha sido que a partir de los 90s, con el descubrimiento de yacimientos de petróleo, la presidencia de Obiang ha tenido los medios económicos para procurarse una narrativa ficticia y positiva sobre su liderazgo. Recientes informes constatan que este presidente ha procurado mejorar su imagen internacional sin atender a los derechos sociales y económicos de su gente, acosando a activistas, imponiendo severas restricciones a la libertad de expresión y minando los derechos políticos (Human Rights Watch). ${ }^{3}$

En este contexto, los escritores de Guinea Ecuatorial han asediado tanto su historia fragmentada como la lejanía de países hispanoparlantes mediante textos en los que se perfila una historia coherente, en donde se rearticulan discursos identitarios de etnia, de hispanidad, de ciudadanía y de nacionalidad ante un panorama cultural disperso. Precisamente, de un esfuerzo de dar coherencia ante la fragmentación y la discontinuidad

coloniales y neocoloniales sobre las que comienza la escritura en español en Guinea, así como una explicación del aislamiento de intelectuales guineanos con respecto a movimientos descolonizadores africanos tales como la Negritude. Ver también "Una conversación entre guineoecuatorianos: Donato Ndongo Bidyogo y Juan Tomás Ávila Laurel”, conducida por Elisa Rizo, para una discusión sobre la pertenencia al hispanismo de la literatura guineana por parte de dos de sus principales exponentes.

2 Ver "State Formation and Trade: The Rise and Fall of the Bubi Polity, c 1840-1910" de Ibrahim Sundiata, en donde se ofrece un estudio de la sistemática y, por mucho tiempo, exitosa resistencia de los bubis de Bioko ante las empresas coloniales.

3 Para un informe del estado de los derechos humanos en Guinea, ver "Submission for the Universal Periodic Review of Equatorial Guinea". Human Rights Watch. Online. September 17, 2013. http://www. hrw.org/world-report-2012/equatorial-guinea.

Revista Iberoamericana, Vol. LXXX, Núms. 248-249, Julio-Diciembre 2014, 745-759 ISSN 0034-9631 (Impreso)

ISSN 2154-4794 (Electrónico) 
se trata en muchas ocasiones la letra iberoamericana. Reclamamos, pues, un corpus relacionado.

Si el reclamo lo hacemos desde la lengua en que se escribe, no asumimos en esta edición ese dato como el imperioso conector entre los mundos hispanohablantes. Antes bien funcionan como loci de parentesco narraciones que se intersectan, tradiciones en consenso, contenidos míticos e incluso búsquedas oxálicas y circunvalantes que son parte de este corpus discursivo que reunimos bajo la ambición de crear conexiones SurSur. Las incidencias en los tropos de movimiento, de distanciación e interrogación de las variopintas relaciones con los centros de poder y la necesidad constante de redefinirse como sujeto articulador, son parte de la confirmación de multiversos compartidos. ${ }^{4}$

En el marco de las narraciones intersectas entre América Latina y de Guinea Ecuatorial sobresale la de la experiencia del negro dentro del hispanismo, como ya lo notaba el escritor, periodista, historiador y crítico literario Donato N'dongo, para quien la literatura guineoecuatoriana:

[...] está llamada a ser el tercer vértice del eje afro-hispano-americano, que configura hoy la geografía lingüística de nuestro idioma común. A poco que se estimule, cumplirá su papel en la tarea de revitalizar la lengua y la cultura en español, que ya no pueden ser comprendidas si las desgajáramos del aporte negro, como demuestran las obras de Nicolás Guillén, Manuel Zapata Olivella, Adalberto Ortiz o Nicómedes Santacruz. (1998, 9)

Innegablemente, a la conexión aquí notada por N'dongo y también subrayada por estudiosos como M'bare N'gom en diversas intervenciones, se suma la dimensión de la diáspora africana. La literatura de Guinea Ecuatorial se encuentra posicionada en la encrucijada del Atlántico Negro ${ }^{5}$ y el hispanismo, y emerge como un espacio conector que no sólo abarca la América Latina, sino incluso otras áreas en donde la experiencia negra e hispana también confluyen. ${ }^{6}$ De manera que Guinea Ecuatorial, su literatura y expresiones culturales son un espacio donde puede leerse la rearticulación no sólo lingüística y cultural de la hispanidad, sino un punto crucial en la construcción de narrativas alternativas de la diáspora africana en las Américas y el mundo. Al atender

4 En el marco de una presentación en un seminario NEH dirigido por Marvin Lewis y James Davies durante el verano del 2008, Rafael Evita, uno de los constituyentes de Guinea Ecuatorial, nos contaba que en el inicio de su exilio en los Estados Unidos durante la dictadura de Macías (1969-1979) él se había identificado más con los centroamericanos que vivían en su área en Washington, DC que con los afroamericanos; si la raza es patria, la lengua es matria.

5 Nos referimos al término acuñado por Paul Leroy en "The Black Atlantic: Modernity and Double Consciousness" (1993).

6 Para una propuesta de tal conexión diaspórica y sus problemáticas, ver "Engaging Equatorial Guinea: Bioko in the Diasporic Imagination" de Ibrahim Sundiata, en Afro-Hispanic Review.

Revista Iberoamericana, Vol. LXXX, Núms. 248-249, Julio-Diciembre 2014, 745-759 ISSN 0034-9631 (Impreso) ISSN 2154-4794 (Electrónico) 
a otras categorías de análisis, como ésta de la diáspora, la aparente lejanía contextual de Guinea Ecuatorial se transforma en invitación urgente a lectores iberoamericanos.

Sin embargo, por ser una literatura que no responde fácilmente a ninguna historia literaria, la de Guinea Ecuatorial reclama su propia historia, su propia teoría. Y en ese proceso, las contempla a todas, las embebe y se construye anónima y tumultuosa. Es una literatura africana e hispana, inscrita en la hendedura entre la francofonía, la comunidad lusófona, el pichinglish del África occidental y las lenguas vernáculas fang, bubi, ndowe, combe y annobonesa. Igualmente, esta es una literatura de conciencia transnacional y poscolonial. A la vez, como ya lo hemos mencionado, la literatura de Guinea Ecuatorial ha sido escrita bajo dictaduras y en su corpus se encuentran narrativas testimoniales y también de replanteamiento historiográfico. Es africana, se señaló antes, pero también es occidental. Es, según Recaredo Silebó Boturu, una literatura "mestiza" donde encontramos algunos movimientos hacia la defensa de epistemologías locales; otros, hacia los cánones occidentales; pero donde la gran mayoría, aunque con singulares matices, apuntan hacia la bifurcación de esas dos tradiciones. Como se ha puntualizado en numerosas intervenciones de los estudios publicados y las conferencias organizadas por Marvin Lewis, por M'bare N'gom, así como por otros investigadores como Landry-Miampika, Michael Ugarte, Dorothy Odartey, Dosinda García Alvite, Joanna Boampong, Benita Sampedro y Baltasar Fra Molinero, esta historia se constituye desde diversas coordenadas dentro y fuera de África. Pero sobre todo, la historia de la literatura guineana se constituye dentro de Guinea Ecuatorial, donde las fronteras internas, la ciudad, la articulación de la voz femenina, el exilio y la censura son vasos comunicantes con productos de las literaturas del siglo veinte.

La problemática relación entre la literatura guineana y otras historias literarias se inicia desde la misma circunstancia de su etapa colonial pues, como nos recuerda Eduardo Subirats, a diferencia de la narrativa de cruzada que distingue la campaña colonial en las Américas:

[1]a colonización de Asia y de África en los siglos siguientes seguía sosteniéndose en el cristianismo como último sistema de legitimación, pero se articulaba en torno a las compañías industriales y comerciales, y en base a una legislación universal que protegía sus monopolios. (173)

En esta modalidad colonial, el racionalismo científico y económico (Subirats 175) surge como epistemología definidora de las regulaciones impuestas a las sociedades ocupadas. Esta dinámica fue, en el contexto de la Guinea Española, fuertemente inspirada en el colonialismo francés (Martin-Márquez 52-60) y definió de manera decisiva el discurso neocolonial de los gobiernos dictatoriales del país en su era independiente, sobre todo el que hoy día gobierna. Así, tenemos hoy un discurso demagógico por parte del gobierno guineoecuatoriano en el que el presidente declara la importancia de la

Revista Iberoamericana, Vol. LXXX, Núms. 248-249, Julio-Diciembre 2014, 745-759 ISSN 0034-9631 (Impreso) 
educación y la cultura para acceder a la modernidad, al mismo tiempo que subraya la responsabilidad de los intelectuales de servir a los objetivos gubernamentales. ${ }^{7}$

Aunque hay autores que se han adherido a esa causa presidencial, la mayor parte de la literatura guineana no obedece a tal llamado y ataca desde diferentes ángulos la narrativa homogeneizadora, ya propuesta por el estado, ya por las imágenes occidentales atribuidas a África. De manera significativa, la literatura contemporánea de Guinea Ecuatorial, más y más, atiende a la heterogeneidad poblacional al actualizar sus discursos identitarios, ya no sólo dependientes de la étnica y la lengua. Por un lado, existen esfuerzos por rescatar las culturas locales de una población cuya mayoría se identifica como fang, ${ }^{8}$ pero en donde también hay otras identidades étnicas y lingüísticas que poseen parte de la memoria colectiva del país: el pueblo bubi, los fernandinos-descendientes de cimarrones traídos por buques antiesclavistas ingleses de la costa occidental- los annoboneses y en menor número, los bisio y los ndowe. Por otro lado, la misma literatura incorpora otras dimensiones del diverso panorama demográfico guineano, como la presencia de europeos y migrantes de países vecinos. ${ }^{9}$ Igualmente, se incorporan al imaginario guineano grupos recientemente atraídos por el petróleo: norteamericanos, chinos y filipinos, entre otros, que ya conforman parte del paisaje poblacional.

En esta instancia de multiplicidad identitaria, la decisión de escribir en español descubre, como lo enuncia la escritora Trinidad Morgades, una estrategia discursiva:

Y si consideramos que el mundo en que vivimos hoy, tiene una necesidad vital de integrarse en grandes unidades políticas, económicas y culturales, porque la unión hace la fuerza, nosotros, los guineanos y el resto del mundo de la Hispanidad, comprenderemos por qué hemos de recurrir a la Hispanidad en busca de valores que nos lleven a una acción común, a fin de conseguir realizaciones prácticas y esperanzadoras para un mundo futuro mejor planificado y organizado. (39-40)

Pero tal estrategia de unificación a la hispanidad para adquirir fortaleza no ha sido una empresa fácil, o siquiera posible. La historia de la literatura escrita en español en Guinea Ecuatorial, lejos de ser un proyecto armonioso, es la de una escritura tortuosamente formada entre dictadura, exilio e insilio, entre disidentes políticos y miembros cercanos al grupo en el poder. Será la historia de una narrativa marginal y no leída ni reconocida entre los hispanohablantes que contrasta con otra de carácter

7 Ver "Discurso con ocasión del manifiesto de adhesión de los intelectuales equatoguineanos", por Teodoro Obiang en Guinea Ecuatorial, país joven (351).

8 Dentro del grupo fang, el clan específico de la villa de Mongomo, por su cercanía familiar tanto a Francisco Macías Nguema como a Teodoro Obiang Nguema, forman gran parte de la oligarquía que ha mantenido el poder político durante los cincuenta años de república en Guinea Ecuatorial.

9 Ver "Hispanic and Bantu Inheritance, Trauma, Dispersal and Return: Some Contributions to a Sense of National Identity in Equatorial Guinea" de Igor Cusack.

Revista Iberoamericana, Vol. LXXX, Núms. 248-249, Julio-Diciembre 2014, 745-759 ISSN 0034-9631 (Impreso)

ISSN 2154-4794 (Electrónico) 
infraestructural y materializada en construcciones de grandes edificios, signo del ya mencionado poder económico obtenido por la presidencia de Obiang a partir del boom petrolero comenzado en los noventas. ${ }^{10}$

II.

Para esbozar, aunque sea muy sucintamente, la historia de la literatura de Guinea Ecuatorial habría que iniciar con el reconocimiento de la existencia pre-hispánica de ricas oraturas provenientes de todos los grupos étnicos que habitan el territorio. De hecho, los inicios de la literatura escrita en castellano dentro del contexto colonial en Guinea Ecuatorial tienen una fuerte conexión con tales tradiciones. De gran importancia en este punto, aunque bajo el vigilante ojo colonial, fue la publicación La Guinea Española fundada a principios del siglo xx por monjes claretianos y que sólo para 1947 comienza a publicar voces guineanas. En un principio, jóvenes seminaristas y estudiantes guineanos recogían las tradiciones orales de la voz autorizada del griot. Sin embargo, fueron voces como la de Esteban Bualo, entre otros, las que empezaron a formar un híbrido entre las narraciones orales y la voz articulada por el ojo del español colonizador. ${ }^{11}$

Igualmente, la conflictiva relación entre colono y colonizado marcará las primeras novelas escritas por indígenas. El ambiguo y sutil repertorio de referencias a la cultura autóctona y colonial de estas primeras narrativas es tema de debate entre especialistas de esta literatura, pues a estas novelas se les atribuye simultáneamente una agenda de resistencia a la colonia, por parte de algunos, y de propaganda de la misma, por parte de otros. ${ }^{12}$ En términos de la historia contada, Cuando los combes luchaban (1953) de Leoncio Evita junto a Una lanza por el boabi (1962) de Daniel Jones Mathama narran la incómoda relación entre las costumbres tradicionales y la presencia europea. En el caso de Evita, se narra la presencia en la región continental de Guinea de unos misioneros bautistas y su enfrentamiento ante el culto Bweti; en el de Jones Mathama, se cuenta el esfuerzo inútil por la recuperación del mundo de la infancia, tema que se tornará recurrente en la escritura guineoecuatoriana.

Esta tensión colonial desaparece tras la independencia, al ser sustituida a partir del abrupto comienzo de la dictadura de Macías Nguema por el tema del exilio. En esta

10 Para un análisis social de la sociedad guineana bajo la dictadura ver "Diccionario básico, y aleatorio, de la dictadura guineana" de Juan Tomás Ávila Laurel.

11 Ver "The Missing Link: African Hispanism at the Dawn of the Millennium" de M'bare N'gom, en base a observaciones textuales de La Guinea Española, número 1165, 10 de enero de 1944 y número 1236, 10 de enero de 1947: 13-15. Allí se discuten las circunstancias de vigilancia colonial bajo las que escribían los participantes de estos certámenes organizados por los claretianos. También ver "Guineanos y españoles en la interacción colonial (1900-1968)" de Donato Ndongo.

12 Ver el "Prólogo" de Elisa Rizo en Caminos y veredas: narrativas de Guinea Ecuatorial 17-18.

Revista Iberoamericana, Vol. LXXX, Núms. 248-249, Julio-Diciembre 2014, 745-759 ISSN 0034-9631 (Impreso)

ISSN 2154-4794 (Electrónico) 
coyuntura histórica, Madrid será la ciudad elegida por disidentes guineanos, como París lo fue para otros migrantes africanos. Por entonces, la capital española vivía su propio régimen dictatorial lo que implica que los textos de los guineanos seguían siendo escritos para la censura. A finales de los 1970's, los jóvenes Donato N'dongo y Francisco Zamora Loboch publican independientemente el pequeño tomo Nueva narrativa guineana (1977) que inserta desde ese momento temas históricos como el tráfico de esclavos ( $\mathrm{La}$ travesía de N'dongo) o la violencia hacia el cuerpo femenino africano (Bea de Zamora) en esta literatura. Completan este momento de escritura dispersa, un rico corpus lírico que incluye gran cantidad de poemas como "Prisionero de la Gran Vía" de Francisco Zamora Loboch (por mencionar solo uno), y la colección poética Ceiba (1978) de la española-guineoecuatoriana Raquel Ilonbé. Igualmente, los ensayos Historia y tragedia de Guinea Ecuatorial (1977) de N'dongo y ¿Dónde estás Guinea? (1978) de Juan Balboa Boneke son publicados en una fase de aparente apertura a la libre expresión en el exilio, aunque se desarrollan contra la dura realidad de subsistencia cotidiana que enfrenta el guineoecuatoriano en la transición de la España franquista al "destape".

Tras la caída de Macías Nguema a manos de su sobrino y actual presidente, Teodoro Obiang, y una vez asentada la normativa y preceptiva dictatorial se publica Ekomo (1985) de María N'sué. Este texto de lirismo, ágil narrativa y escritura decidida nos coloca en una literatura poscolonial que ya nada envidia, por su tratamiento de temas tanto de género como de repertorios orales, a las literaturas con más amplia tradición. Es entonces que da inicio a un proceso de reflexión sobre el pasado inmediato de la dictadura de Macías. En ese ambiente, Juan Balboa Boneke publica El reencuentro: el retorno del exiliado (1985) con lo que nos dará uno de los temas principales de esta escritura de exilio: la imposibilidad del regreso al punto de origen. Por su parte, la novela Las tinieblas de tu memoria negra (1987) de N'dongo incluirá el gesto autobiográfico que definirá mucha de esta escritura, la mirada del niño que encuentra un mundo desarticulado y que sólo el exilio hace de alguna manera posible. Esta misma vena retrospectiva sobre la dictadura de Macías es heredada por la siguiente generación de escritores. Sobresalen las novelas Áwala cu sangui $(2000,2010)$ y Arde el monte de noche (2009) de Juan Tomás Ávila Laurel. En ellas, un lenguaje poético e irónico, donde irrumpe el misterio y el realismo, cuenta las historias familiares por donde se ventila el sufrimiento annobonés durante los "años de silencio", frase con la que acuña N'dongo la duración de la dictadura maciísta.

Además de la revisión del pasado inmediato de la dictadura anterior, existe otra tendencia en la literatura reciente hacia el alejamiento temático de la experiencia de la primera dictadura (de Macías) para entablar una reflexión de la historia, tanto colonial como poscolonial, del país. En esta vertiente destacan las novelas La carga (1999) de Juan Tomás Ávila Laurel y Retrato con un infiel (2007) de José Fernando Siale Djangany; y el drama Y cruzó el aire (2010) también de Ávila Laurel. En estos textos, los autores nos remontan a la era colonial para replantear la convivencia entre españoles

Revista Iberoamericana, Vol. LXXX, Núms. 248-249, Julio-Diciembre 2014, 745-759 ISSN 0034-9631 (Impreso) ISSN 2154-4794 (Electrónico) 
y guineanos. Con un tono sarcástico e intrincadas estructuras narrativas, Ávila y Siale trazan una nueva narrativa del origen nacional desde un marco que subraya la agencia de la población guineoecuatoriana (Rizo 22).

La literatura guineoecuatoriana de fines del siglo xx, sobre todo entre los escritores que viven dentro del territorio nacional, asignan a la ciudad de Malabo y la isla de Bioko en general el signo de lo bifurcado tanto en lo relativo a la economía mundial desde siglos atrás como culturas, ideologías, pasiones, miedos y placeres. Es una literatura que responde al acelerado ritmo de hibridación impuesto por la implantación de órdenes globales. La ciudad de Malabo, y su relación con todas las urbes del mundo, emerge como máquina de significados resultando en una fuente de interrogación, diálogo y reflexión sobre latrocinios, encuentros culturales, confrontación y conciliación. Además de los ya nombrados Siale y Ávila Laurel, sobresalen otras voces, como Maximiliano Nkogo, autor de la colección de relatos Adjá-Adjá y compañero en un 3 de agosto (1994) y la novela Nambula (2006). En sus textos, Nkogo examina las estructuras internas que sustentan el poder oligárquico desde las intrincadas relaciones dentro de la familia del mandatario hasta la infraestructura burocrática y policial que se consume en una obsesión de vigilar a la población y a sí misma.

Por su parte, César Mba construye un mundo de ficción encauzado por alusiones del mundo literario para dar una respuesta cosmopolita desde Guinea a los diálogos intelectuales a nivel mundial. En su Porteador de Marlow (2008) convergen múltiples referencias a escritores de habla inglesa, alemana, francesa e hispana. Significativamente, Mba reclama como referencia a autores de otros lares, especialmente a los latinoamericanos Jorge Luis Borges y Roberto Bolaño, guiño que, por un lado, apunta a la continuidad entre la literatura guineoecuatoriana y la latinoamericana, y que, por el otro, revela su predilección por temas universales, sin perder sus referencias al ambiente del contexto local. Este gesto de declarase sucesor de otras literaturas, de vivir la ciudad letrada antes que ninguna otra, explica otros autores como Trinidad Mogades heredera de Sófocles, por ejemplo. El caso de Mba, las letras se convierten en una geografía que trasciende la dicotomía Macías/Obiang para preguntarse sobre la no pertenencia del africano intelectual exílico, quien debe atender adopciones tribales, tras entenderse como sujeto de la escritura.

Una autora que también sobresale es la controversial Guillermina Mekuy, quien en sus novelas El llanto de la perra (2005), Las tres vírgenes de Santo Tomás (2008) y Tres almas para un corazón (2011) presenta una serie de narraciones atractivas y de gran éxito editorial que ilustran la transformación de la sexualidad femenina y el poder de la mujer dentro de los pudientes grupos oligárquicos. Estas son narraciones donde contrastan el libertinaje y tradiciones ultra conservadoras como la poligamia. La defensa de la libertad erótica e intelectual femenina y el simultáneo acatamiento de formatos tradicionales se resuelven en la escritura de Mekuy gracias a un relato

Revista Iberoamericana, Vol. LXXX, Núms. 248-249, Julio-Diciembre 2014, 745-759 ISSN 0034-9631 (Impreso) 
intimista de soluciones personales, y reivindicaciones del yo psicológico al adoptar el mundo tradicional.

Finalmente, un pilar importante en la vida cultural de Guinea Ecuatorial lo provee la obra del joven Recaredo Silebo Boturu. Este poeta, dramaturgo, narrador, actor y director teatral ofrece en sus libros Luz en la oscuridad (2010) y Crónicas de memorias anuladas (2014, en prensa) una línea comprometida con la justicia social, pero no solo a nivel de lo local, sino en constante dialogo con las fuerzas globalizadoras. A diferencia de las alusiones literarias de Mba, la opción cosmopolita de Boturu acude a referencias de la cultura popular, de los analfabetas y los parias del mundo, para establecer un diálogo con los "miserables" del mundo globalizado. En suma, la literatura de Guinea Ecuatorial, como en términos muy generales (y ciertamente de manera incompleta) puede verse aquí, intenta dar sentido a una pasado colonial fragmentado, a un sueño democrático frustrado, a una grotesca realidad globalizadora.

III.

Los estudios sobre la literatura de Guinea Ecuatorial, aunque recientes, forman ya un corpus importante. Algunas de las preguntas que han concernido a investigadores hasta el momento se refieren a la clasificación de esta literatura y su relación con las literaturas hispanas y africanas. Igualmente, en este dossier seguimos ese espíritu de cuestionamiento, de búsqueda de renovadas categorías de análisis, pero sobre todo, de autorreflexión sobre nuestras propias identidades.

Es nuestra responsabilidad dar reconocimiento a los volúmenes académicos dedicados a la literatura de Guinea Ecuatorial que, comenzando con el milenio, han cultivado ya una rica y creciente comunidad de investigadores. En el año 2000 se publica el primer número especial dedicado a esta literatura en los Estados Unidos en la revista AfroHispanic Review. La revista era dirigida entonces por Marvin Lewis y M'bare N'gom fue el editor invitado. A esta importante publicación, siguió Recuperación de la memoria, una antología de ensayos editada también por N'gom. Igualmente significativos fueron los volúmenes de Arizona Journal of Cultural Studies (2004, editado por M'bare N'gom y Michael Ugarte), de Journal of Spanish Cultural Studies (2006, editado por Michael Ugarte y Teresa Vilarós), así como el reciente número especial de Afro-Hispanic Review, de corte multidisciplinario (2010, editado por Benita Sampedro y Baltasar Fra-Molinero). El libro An Introduction to the Literature of Equatorial Guinea: Between colonialism and Dictatorship (2007) de Marvin Lewis, por su parte, constituyó la primera monografía en inglés dedicada a esta literatura y presentó un valioso mapa del corpus literario existente. Gracias al conjunto de textos citados arriba y al total de artículos y libros (más de un centenar) publicados por investigadores de diversas formaciones académicas (peninsularistas, latinoamericanistas, afro-hispanistas, comparativistas, caribeñistas)

Revista Iberoamericana, Vol. LXXX, Núms. 248-249, Julio-Diciembre 2014, 745-759 ISSN 0034-9631 (Impreso)

ISSN 2154-4794 (Electrónico) 
podemos afirmar que ya existe un campo sólido de estudios de la literatura de Guinea Ecuatorial. No sólo eso, se puede sostener que el estudio de esta literatura está borrando, a medida que crece, viejas fronteras académicas. Se torna innegable el hecho de que esta literatura nos coloca frente a la ruptura territorial de los campos de estudio.

Siguiendo los pasos de los múltiples investigadores que han escrito sobre la literatura ecuatoguineana, los colaboradores de este número buscan nuevos puertos de embarque. Los artículos aquí reunidos analizan las condiciones y posibilidades combativas desde las letras sitiadas por la colonia, el hecho independentista, el exilio, el género; exploran el español de Guinea Ecuatorial como un dialecto donde impera la fluidez cultural transatlántica; retan fronteras canónicas - geográficas, de clasificación literaria- para aproximar la literatura de Guinea Ecuatorial. Finalmente, dramaturgos y escritores conversan sobre el fragmentado y casi esperpéntico acceso de la sociedad guineana a la modernidad.

La sección "Propuestas locales ante el fórum independentista del África occidental" incluye las colaboraciones de M'bare N'gom, Dorothy Odartey y Rosario Swanson, mismos que se ocupan de analizar las condiciones y posibilidades combativas desde los espacios de producción sitiados por la colonia, el hecho independentista, el exilio, el género y la escritura misma. Dorothy Odartey nos brinda un valioso artículo en el que atiende a la especificidad de la situación del escritor guineano en relación al del resto del África occidental para plantear un análisis sobre textos fundacionales de Guinea Ecuatorial. Por su parte, M'bare N'gom nos señala en su examen de una de las primeras narraciones de N'dongo un elemento crucial: que desde su nacimiento, la literatura de Guinea Ecuatorial se gesta en el espacio transfronterizo. También en esta sección se incluye la colaboración de Rosario Swanson, quien examina un velado discurso anticolonialista en la novela "Cuando los combes luchaban".

"Juegos transatlánticos: tierra, lírica y canto" incluye colaboraciones dedicadas a la poesía guineoecuatoriana. Por un lado, los ensayos de García Alvite y Pérez toman como punto de asedio la relación simbiótica entre la voz poética y el ambiente para crear un espacio de nuevo significado, uno que posibilita la continuidad de la identidad entre Guinea, a pesar y mediante su exilio español. Por su parte, Cabral explora algunos puentes retóricos viables entre la poesía femenina de Colombia y de Guinea Ecuatorial, atendiendo a la cadena transatlántica que une la historia afro-colombiana con la guineoecuatoriana.

"El español en África y más allá: las otras historias literarias y los otros mapas lingüísticos" contiene la valiosa contribución de John Lipski, quien propone una visión transatlántica para un acercamiento a los elementos con los que el español de Guinea Ecuatorial se erige como un dialecto dentro del hispanismo, nutrido de una variada gama de culturas con las cuales convive. En el campo literario, el ensayo de Joseph Otabela presenta una aproximación actualizada sobre el desarrollo de la literatura guineana desde

Revista Iberoamericana, Vol. LXXX, Núms. 248-249, Julio-Diciembre 2014, 745-759 ISSN 0034-9631 (Impreso) 
la independencia hasta nuestros días. Por su parte, la colaboración de Alain Lawo-Sukam fortalece las bases para el estudio de la literatura hispana escrita en Camerún, ratificando con esto, la eliminación de fronteras que nos regalan las literaturas hispanoafricanas.

En "Sobre el teatro en Guinea Ecuatorial, con saludos a América Latina" aparece el análisis de María Zalduondo, quien reflexiona sobre las epistemologías posibles a partir de la reformulación de la tragedia de Sófocles en el teatro guineoecuatoriano y en el argentino. Por su parte, Elisa Rizo da la palabra a protagonistas del séptimo arte en Guinea Ecuatorial para trazar las coordenadas transnacionales en las que se ha desarrollado el teatro de esta nación a partir de los 90's.

"Pliegos, porosidades: reubicación de fronteras, cánones e historiografías" contiene seis ensayos que retan límites canónicos para aproximar la literatura de Guinea Ecuatorial. Michael Ugarte presenta un estudio comparativo entre una obra camerunesa y otra guineana con el fin de escrutar las singularidades de la formación de un discurso anticolonial en el oeste de África; esto, sin perder de vista las diferencias de la producción de cada obra. Una aproximación comparativa también es la que propone Selena Nobile, quien al llamar la atención sobre puntos de engarce entre las literaturas del exilio africano en España e Italia logra expandir las coordenadas de lecturas posibles de literatura guineoecuatoriana. Por su parte, Cristián Ricci mira hacia las dinámicas internas del desarrollo de la narrativa guineana para proponer un avance teórico con la acuñación del "discurso paródico afro-occidental." Esta sección incluye también la colaboración Nicole Price, quien atiende al cuestionamiento de cánones historiográficos para ocuparse de una novela clave en la formación del canon novelístico guineoecuatoriano: "La carga" de Juan Tomás Ávila Laurel. Concluye esta sección una valiosa apreciación teórica poscolonial de la literatura guineoecuatoriana por parte de Clement Akassi.

"Lecturas y lectores de textos silenciados" incluye colaboraciones que exploran, entre otros aspectos, la convergencia estética de lo escrito, de lo oral y las relaciones lector-texto. Olga Arbeláez propone un análisis de las cartografías alternas que se desprenden de las tres primeras novelas de Donato N'dongo con lo que propone un acercamiento teórico que posibilita un análisis más exacto a las narrativas de éxodo de Guinea Ecuatorial. Clelia Rodríguez nos ofrece un emotivo ensayo sobre la ficcionalización de la oralidad en "Ekomo" de María Nsué. Por su parte, Juan de Urda observa las categorías del lector implícito y el fingido en la obra de Francisco Zamora para subrayar la problemática circunstancia de la recepción de obras guineoecuatorianas escritas desde el exilio. Finalmente, Lola Aponte Ramos deslinda las funciones asignadas al lector desde la escritura de Leoncio Evita, Mathama Davies y Juan Tomás Ávila.

En “La nación rota: visiones desde el insilio/exilio,"los escritores guineoecuatorianos Justo Bolekia, José Fernando Siale, Juan Tomás Ávila Laurel y Recaredo Silebo Boturu reflexionan sobre el fragmentado y casi esperpéntico acceso de la sociedad guineana a la modernidad. Justo Bolekia lo hace con un ensayo de corte antropológico en el

Revista Iberoamericana, Vol. LXXX, Núms. 248-249, Julio-Diciembre 2014, 745-759 ISSN 0034-9631 (Impreso)

ISSN 2154-4794 (Electrónico) 
que destaca las características de un discurso de autodenigración empotrado ya en la mentalidad guineoecuatoriana con el fin de enmarcar un llamado a la recuperación de la cultura inmaterial. Por su parte, Siale adopta un tono etnográfico para analizar los procesos migratorios internos dentro de Guinea Ecuatorial, mientras que Ávila Laurel puntualiza la circunstancia en que se desarrollan las letras guineanas. Finalmente, Boturu asedia esta realidad mediante una crónica personal de la adaptación y puesta en escena de Dezafi de Franketienne en los escenarios de Malabo.

El volumen cierra con la voz de escritoras guineoecuatorianas en sendas entrevistas a Trinidad Morgades y a Guillermina Mekuy. Conversaciones son estas que dan muestra de las muchas y variadas participaciones posibles de la mujer dentro del fórum de la cultura en Guinea Ecuatorial.

Leer hacia Guinea Ecuatorial es un viaje abierto e incompleto. Supone la fabulación continua, la invención de quienes somos, asumirnos como incompletos hasta que demos con esa llave para finalmente resignarnos a que el destino final sea la identidad no fija. Como propuso Nietzsche: no hay datos, solo interpretaciones. Si como ya sabemos toda regionalización y periodización histórico-geográfica supone una comunidad imaginaria, cualquier narrativa que nos haga sentido se vuelve nuestra matria. Asumir ruptura e incomplitud es la invocación de este número especial de la Revista Iberoamericana. Y de ese reconocimiento que prosigan los diálogos, la recreación de horizontes, pues como propuso Heidegger todo lo que vamos desdoblando se acerca y se aleja. De un lado aprenderemos de una nueva frontera literaria. De otro lado, la mutabilidad misma nos hará conscientes de la complejidad en las diferenciaciones de mundos. Las coeditoras extienden su más sincero agradecimiento a todos los colaboradores de este proyecto y especialmente a la Revista Iberoamericana por abrir sus puertas a los estudios literarios y culturales sobre Guinea Ecuatorial.

\section{OBRAS CITADAS}

Ávila Laurel, Juan Tomás. Diccionario básico, y aleatorio, de la dictadura guineana.

Barcelona: Laboratorio de recursos orales, 2012. Arde el monte de noche. Madrid: Calambur, 2009. La carga. Valencia: Ediciones Palmart, 1999.

"Y cruzó el aire". La palabra y la memoria: Guinea Ecuatorial 25 años después.

Landry Wilfrid Miampika, ed. Madrid: Verbum, 2010.

Áwala cu sangui. Letras Transversales: obras escogidas de Juan Tomás Ávila

Laurel. Segunda Edición. Elisa Rizo, ed. Madrid: Verbum, 2011.

Boneke, Juan Balboa. El reencuentro: el retorno del exiliado. Fuenlabrada: Anzos, 1985. Boturu, Recaredo S. Luz en la noche: poesía y teatro. Madrid: Editorial Verbum, 2010. Crónicas de memorias anuladas: poesía y teatro. Elisa Rizo, ed. Madrid: Editorial Verbum, 2014. En prensa.

Revista Iberoamericana, Vol. LXXX, Núms. 248-249, Julio-Diciembre 2014, 745-759 ISSN 0034-9631 (Impreso)

ISSN 2154-4794 (Electrónico) 
Cusack, Igor. "Hispanic and Bantu Inheritance, Trauma, Dispersal and Return: Some Contributions to a Sense of National Identity in Equatorial Guinea". Nations and Nationalism 5 (1999): 207-36.

Evita, Leoncio. Cuando los combes luchaban: novela de costumbres de la Guinea Ecuatorial. Madrid: Consejo Superior de Investigaciones Científicas, 1953.

Ilonbé, Raquel. Ceiba. Editorial Madrid, 1978.

Jones Mathama, Daniel. Una lanza por el Boabí. Barcelona: Casals S.L., 1962.

Lewis, Marvin. An Introduction to the Literature of Equatorial Guinea: Between Colonialism and Dictatorship. Columbia: U of Missouri P, 2007.

Lininger, Max. Historical Dictionary of Equatorial Guinea. London: The Scarecrow Press, Inc., 1979.

Mba, César. El porteador de Marlow: canción negra sin color. Madrid: Sial, 2007.

Mekuy, Guillermina. El llanto de la perra. Barcelona: Plaza y Janés, 2005. Las tres vírgenes de Santo Tomás. Madrid: Suma de letras, 2008.

Tres almas para un corazón. Barcelona: Martinez Roca, 2011.

Morgades Besari, Trinidad. "Guinea Ecuatorial y la hispanidad". Africa 2000 II/1 (1987): 39-41.

Martin-Marquez, Susan. Desorientations: Spanish Colonialism in Africa and the Performance of Identity. New Haven: Yale UP, 2008.

Ndongo-Bidyogo, Donato. La travesía, El sueño. Madrid: Nueva narrativa Guineana, 1977.

Las tinieblas de tu memoria negra. Madrid: Fundamentos, 1987.

Historia y tragedia de Guinea Ecuatorial. Madrid: Editorial Cambio 16, 1977.

"Guineanos y españoles en la interacción colonial (1900-1968)". España en

Guinea. Donato Ndongo y Mariano de Castro, eds. España: Sequitur, 1998. 107-217.

y Mbare Ngom. Literatura de Guinea Ecuatorial (Antología). Madrid: Colección

Casa África, Sial Editores, 2000.

N'gom Faye, M'bare. "The Missing Link: African Hispanism at the Dawn of the millennium.” Arachne@Rutgers: Journal of Iberian and latin American Literary and Cultural Studies 1/1 (2001): 1-19. <http://arachne.rutgers.edu/concept.htm> 13 mayo 2014.

Nkogo, Maximiliano. Adjá-Adjá y compañero (1994) y Adjá-Adjá y compañero en un 3 de agosto (1994).

Námbula. Malabo: Centro Cultural Español, 2006.

Nsué, María. Ekomo. Madrid: Universidad Nacional de Educación a Distancia(UNED), 1985.

Siale Djangany, José Fernando. Autorretrato con un infiel. Barcelona: El Cobre, 2007. Rizo, Elisa. "Prólogo". Caminos y Veredas: Narrativas de Guinea Ecuatorial. México: UNAM, 2011.

Revista Iberoamericana, Vol. LXXX, Núms. 248-249, Julio-Diciembre 2014, 745-759 ISSN 0034-9631 (Impreso)

ISSN 2154-4794 (Electrónico) 
"Diálogo entre guineoecuatorianos: una conversación con Donato Ndongo y Juan Tomás Ávila Laurel”. Journal of Spanish Cultural Studies 7/3 (2006): 259-270.

Subirats, Eduardo. “Colonialismo: Comercio, cristianismo y civilización”. Afro-Hispanic Review 28 (2009): 173-178.

Sundiata, Ibrahim. "State Formation and Trade: The Rise and Fall of the Bubi Polity, c 1840-1910." The International Journal of African Historical Studies 27/3 (1994): 505-523.

"Engaging Equatorial Guinea: Bioko in the Diasporic Imagination." Afro-Hispanic Review 28 (2009): 131-142.

Obiang Nguema Mbasongo, Teodoro. Guinea Ecuatorial, País Joven. Malabo: Ediciones Guinea, 1985.

Zamora Loboch, Francisco. "Bea.” Madrid: Nueva narrativa Guineana, 1977.

Bibliografía SELECTA DE NÚMEROS ESPECIALES EN REVISTAS ACADÉMICAS, LIBROS DE ENTREVISTAS, ANTOLOGÍAS LITERARIAS Y MONOGRAFÍAS EN EL CAMPO DE ESTUDIOS LITERARIOS GUINEOECUATORIANOS.

Álvarez Méndez, Natalia. Palabras desencadenadas. Aproximación a la teoría postcolonialy a la escritura hispano-negroafricana. Zaragoza: Prensas Universitarias de Zaragoza, 2010.

Avome Mba, Giséle. Lectura socio-semiótica del teatro postcolonial de Juan Tomas Ávila Laurel: entre la sátira y la subversión. Laboratorio de recursos orales. Barcelona: Ceiba, 2012.

Lewis, Marvin A. An Introduction to the Literature of Equatorial Guinea: Between Colonialism and Dictatorship. Columbia: U of Missouri P, 2007.

Lifshey, Adam. The Magallan Fallacy: Globalization and the Emergence of Asian and African Literature in Spanish. Ann Arbor: U of Michigan P, 2012.

Miampika, Wilfrid-Landry, ed. La palabra y la memoria: Guinea Ecuatorial 25 años después. Madrid: Verbum, 2010.

Miampika, Wilfrid-Landry y PatriciaArroyo, eds. De Guinea Ecuatorial a las literaturas hispanoafricanas. Madrid: Verbum, 2010.

N'gom Fayé, M'bare, ed. Palabra abierta: conversaciones con escritores africanos de expresión en español. Madrid: Editorial Verbum, 2013.

La recuperación de la memoria: creación cultural e identidad nacional en la literatura hispano-negroafricana. Alcalá de Henares: Universidad de Alcalá de Henares, 2004.

y Gloria Nistal. Nueva antología de la literatura de Guinea Ecuatorial. Madrid: SIAL, 2012.

y Michael Ugarte, eds. Arizona Journal of Hispanic Cultural Studies 8 (2004).

Revista Iberoamericana, Vol. LXXX, Núms. 248-249, Julio-Diciembre 2014, 745-759 ISSN 0034-9631 (Impreso) 
"Equatorial Guinean Literature [Special Issue]". Afro-Hispanic Review 19/1 (2000 Spring).

Otabela, Joseph Desiré. Entre estética y compromiso: la obra de Donato NdongoBidyogo. Madrid: UNED, 2009.

Rizo, Elisa, ed. Caminos y Veredas: Narrativas de Guinea Ecuatorial. México: UNAM, 2011.

ed. Letras Transversales: Obras escogidas de Juan Tomás Avila Laurel. Madrid: Verbum, 2012.

ed. Crónicas de lágrimas olvidadas: poesía y teatro. Madrid: Verbum. En prensa.

Sampedro Vizcaya, Benita y Baltasar Fra-Molinero, eds. "Equatorial Guinea [Número especial]". Afro-Hispanic Review 28/2 (2009).

Ugarte, Michael y Teresa Vilarós, eds. “African Spain [Número especial].” Journal of Spanish Cultural Studies 7/3 (2006).

Ugarte, Michael. Africans in Europe: The Culture of Exile and Emigration from Equatorial Guinea to Spain. Chicago: U of Illinois P, 2010. 
